\title{
Preparation of Multifunctional Al-Mg Alloy Surface with Hierarchical Micro/nanostructures by Selective Chemical Etching Processes
}

Tian Shi ${ }^{\mathrm{a}}$, Jianyi Kong ${ }^{\mathrm{a}}$, Xingdong Wang ${ }^{\mathrm{a}}$, Xuewu $\mathrm{Li}^{\mathrm{b}, *}$

${ }^{a}$ School of Machinery and Automation, Wuhan University of Science and Technology, 947 Peace Avenue, Wuhan 430081, PR China

${ }^{\mathrm{b}}$ School of Mechanical and Electronic Engineering, Wuhan University of Technology, 122 Luoshi Road, Wuhan 430070, PR China

\begin{abstract}
A superamphiphobic aluminium magnesium alloy surface with enhanced anticorrosion behavior has been prepared in this work via a simple and low-cost method. By successively polishing, etching and boiling treatments, the multifunctional hierarchical binary structures composed of the labyrinth-like concave-convex microstructures and twisty nanoflakes have been prepared. Results indicate that a superhydrophobic contact angle of $160.5^{\circ}$ and superoleophobic contact angle larger than $150^{\circ}$ as well as low adhesive property to liquids are achieved after such structures being modified with fluoroalkyl-silane. Furthermore, the anticorrosion behaviors in seawater of the as-prepared samples are characterized by electrochemical tests including the electrochemical impedance spectroscopy, equivalent circuits fitting and potentiodynamic polarization curve. It is found that the hierarchical micro/nanostructures accompanying with the modified coating are proved to possess the maximal coating coverage rate of $90.0 \%$ larger than microstructures of $85.9 \%$, nanostructures of $83.8 \%$ and bare polished surface of $67.1 \%$ suggesting the optimal anticorrosion. Finally, a great potential application in concentrators for surface-enhanced Raman scattering (SERS) analysis of toxic and pollutive ions on the superamphiphobic surface is also confirmed. This work has wider significance in extending further applications of alloys in engineering and environmental detecting fields.
\end{abstract}

Keywords: Superamphiphobic, Micro/nanostructure, Anticorrosion, Concentrator, Al-Mg alloy

* Corresponding author.

E-mail: lixuewu55@126.com. Tel.: +86-27-68862478. 


\section{Introduction}

Recent decades have seen a gradually increased application of Aluminium magnesium alloys (Al-Mg alloys) in engineering fields due to their excellent physical, chemical and mechanical properties of bright color, high specific intensity, good workability, corrosion resistance, no low temperature brittleness and magnetism, high electrical and thermal conductivity [1-5]. Especially for the field of naval architecture and ocean engineering, $\mathrm{Al}-\mathrm{Mg}$ alloys are pervasively used for shipbuilding structural parts, plate and shell structures, welding structures, pressure vessels and marine transport pan cans [6,7]. The reactive chlorine ions abounding in seawater, however, can preferential adsorb and destroy the protective passivation membrane on alloys surfaces leading to the pitting corrosion failure [8,9]. So, the application fields as well as the working life of this typical engineering material are severely restricted.

The study for protecting alloys from corrosion in seawater is of great significance. As yet, the methods of protective coating [10], surface oxidization [11,12], mechanical alloying [13-15] aged-hardening heat treatment $[4,8]$ and the accretion of corrosion inhibitors $[16,17]$ have been applied to improve anticorrosion behavior of Al-Mg alloys. Besides, Rasouli et al. have applied the friction stir processing to render AA5083 Al-Mg alloy an improved anticorrosion behavior [18]. Zazi et al. have fabricated a 5083-H321 Al-Mg alloy with a good repelling property to seawater through thermomechanical treatments [19]. Trdan et al. have investigated the effect of laser shock peening on the dislocation transitions, grain refinement as well as corrosion resistance of Al-Mg alloys [20]. Among these protective methods, however, electroplating coating with heavy metal ions is environmentally polluting. The implementation process of micro-arc oxidation is under high voltage, strong current posing a safety hazard. Samples are 
easily oxidized in the process of mechanical alloying and also the ball mill parts will cause the pollution of alloys samples to some extent. While for laser engineering, it may be costly and hard to control. For these reasons, the way to develop a simple and low-cost anticorrosion method for Al-Mg alloys is still a big challenge.

Recent years have seen some surface coating techniques, such as organic/inorganic hybrid nanocomposite membranes [21], conductive polyaniline anticorrosion coatings [22], chemical conversion coatings [23], superhydrophobic membranes [24] and self-assembled monomolecular films [25], among which the superhydrophobic surfaces can achieve unique wettability and also provide a promising method to repel corrosive mediums. Inspired by surfaces of butterfly wings and rose petals exhibiting perfect wettability, the preparation of micro/nanostructures accompanying by the modified low surface energy coatings can achieve the desired wettability on engineering materials surfaces. Recently, various methods including the physical methods of high speed wire electrical discharge machining [26], electrospinning [27], laser machining [28] and the chemical methods of anodic oxidation [29], sol-gel [30], electrochemical etching [31], hydrothermal synthesis [32] and hybrid organic-inorganic coatings [33] have been reported to fabricate surfaces with superior wettability on aluminum alloys plates. However, the anticorrosion behavior of the prepared surfaces in seawater or some other oily corrosive mediums is seldom mentioned in above works despite of their superhydrophobicity. Even some works have reported the anticorrosion property, but a markedly decreased corrosion rate of substrates cannot be found.

In this work, a low-cost and simple method is developed to render $\mathrm{Al}-\mathrm{Mg}$ alloys surfaces not merely superhydrophobicity but also superoleophobicity. The hierarchical binary structures with labyrinth-like tridimensional microstructures and twisty nanoflakes are firstly obtained by 
successively polishing, etching and boiling treatments. After fluoroalkyl-silane modification of the as-prepared surfaces, the superamphiphobicity is finally achieved. Moreover, the improved anticorrosion behavior of the fabricated surface in seawater is electrochemically assessed. Finally, the fabricated surface is also proved to possess a great potential application in concentrators for SERS analysis of toxic and pollutive ions.

\section{Experimental section}

\subsection{Materials}

Al-Mg alloys plates $\left(10 \times 10 \times 2 \mathrm{~mm}^{3}\right)$ with major elements of $95.7 \mathrm{wt} \% \mathrm{Al}$ and $3.1 \mathrm{wt} \%$ Mg were used. Surface modifier of $1 \mathrm{H}, 1 \mathrm{H}, 2 \mathrm{H}, 2 \mathrm{H}-\mathrm{Perfluorodecyltrichlorosilane} \mathrm{was} \mathrm{purchased}$ from Shanghai Aladdin Biological Technology Co., Ltd., China. Deionized water was made by a Millipore water purification system (MilliQ, specific resistivity of $18.25 \mathrm{M} \Omega . \mathrm{cm}$, S.A., Molsheim, France). Other experimental chemicals reagents were of analytical grade and obtained from Sinopharm Chemical Reagent Co., Ltd., China.

\subsection{Procedures}

Firstly, Al-Mg alloys plates were cleaned with deionized water, acetone and ethanol after being polished with W40, W20, W10 and W3.5 abrasive papers in sequence (labeled as "P" processing). Then, the etching processing (labeled as "E" processing) was conducted by immersing the cleaned plates into $4 \mathrm{M}$ hydrochloric acid solution for $18 \mathrm{~min}$. After that, samples must be immediately rinsed with deionized water and then dried with high purity nitrogen. Thirdly, the boiling processing (labeled as "B" processing) was proceeded by putting the etched samples into boiling deionized water for $60 \mathrm{~s}$ and then dried with nitrogen. Finally, the fluoroalkyl-silane modification processing (labeled as "F" processing) was carried out by 
immersing the as-prepared samples into the ethanol solution of $20 \mathrm{mM}$ $1 \mathrm{H}, 1 \mathrm{H}, 2 \mathrm{H}, 2 \mathrm{H}-$ Perfluorodecyltrichlorosilane for $12 \mathrm{~h}$ and then heated at $100{ }^{\circ} \mathrm{C}$ for $2 \mathrm{~h}$. All the processings were conducted at room temperature (about $5{ }^{\circ} \mathrm{C}$, winter of Central China)

\subsection{Characterization}

The Field Emission Scanning Electron Microscope (FESEM, Ultra Plus-43-13) equipped with an energy dispersive X-ray spectrometer (EDX) were used to characterize the morphologies and compositions of the prepared Al-Mg alloys surfaces. An OCA20 system (Dataphysics $\mathrm{GmbH}$, Germany) was employed to measure the static contact angle $\left(\theta_{c}\right)$ of a droplet $(5 \mu \mathrm{L})$. And also the $\theta_{c}$ value for each surface was calculated by averaging the repeat tests for ten times. The Fourier-transform Infrared Spectrophotometer (FTIR, JASCO, Japan) was used to characterize the chemical composition of the modified surface. A three-dimensional noncontact surface profiler (NanoView-E1000, Korea) was used to characterize morphologic images and roughness of prepared surfaces. The electrochemical workstation (CHI660D, Shanghai Chen Hua Instrument Co., Ltd., China) was applied to conduct the electrochemical measurements of electrochemical impedance spectroscopy (EIS) and potentiodynamic polarization curves in $3.5 \mathrm{wt} \%$ seawater. A standard three-electrode system including a Pt net counter electrode, a saturated calomel reference electrode and a working electrode of the treated sheet with exposing area of $1 \mathrm{~cm}^{2}$ in seawater was applied in the electrochemical tests. SERS tests were conducted via a confocal microprobe Raman system (LabRam HR800) using a laser $(632.85 \mathrm{~nm})$ and an objective lens $(50 \times$, numerical aperture of $0.5)$.

\section{Results and discussion}




\subsection{Preparation of superamphiphobic surface}

FESEM images of the Al-Mg alloys surfaces processed with different steps are exhibited in

Fig. 1. The morphologies with different magnifications of the bare polished surface are shown in Fig 1a, which depicts a relatively smooth surface. Contrastly, different surface structures with equally distributed twisty flakes with ridge size of about $100 \mathrm{~nm}$ accompanying with some porous structures are clearly observed after the polished sample being immersed into boiling deionized water for $60 \mathrm{~s}$, as shown in Fig. 1b. Actually, the substrate surface can react chemically with water under boiling conditions to generate $\mathrm{Al}_{2} \mathrm{O}_{3} \cdot \mathrm{xH}_{2} \mathrm{O}\left(\mathrm{Al}+\mathrm{H}_{2} \mathrm{O} \rightarrow\right.$ $\mathrm{A}_{2} \mathrm{O}_{3} \cdot \mathrm{xH}_{2} \mathrm{O}+\mathrm{H}_{2} \uparrow$ ), which further reacts with water leading to the formation of boehmite crystals. Meanwhile, hydrogen and bubbles can physically attack the dissolvable boehmite as well as substrate surface resulting in the development of rough nanoflakes and caverns. Fig. 1c shows the surface morphologies with different magnifications of the polished sample after being immersed into $\mathrm{HCl}$ solution for $18 \mathrm{~min}$. Obviously, the roughly hierarchical labyrinth-like convex/concave structures with the ridge size of about $2 \mu \mathrm{m}$ are attained. As a common crystal metal, Al-Mg alloys inherently contain many high-energy dislocations and line defects, which can be preferentially attacked and dissolved in etchant than any other sites. The hierarchical microstructures can just gradually form on substrate surface due to the above selective etching effect. Different from the above angular etching structures in Fig. 1c, the labyrinth-like convex/concave microstructures covered with the twisty nanoflakes are finally achieved with the further immersing treatment in boiling deionized water for $60 \mathrm{~s}$, as depicted in Fig. 1d. These typical binary hierarchical micro/nanostructures will present a great perspective in superamphiphobic function realization on $\mathrm{Al}-\mathrm{Mg}$ alloys surfaces.

Generally, alkylsilane modification on a surface is an effective method to prepare low 
surface energy coating for an enhanced surface wettability. Herein, the Al-Mg alloys surfaces with different treatments have been modified with fluoroalkyl-silane and also the corresponding wettability have been characterized by $\theta_{c}$ values $(5 \mu \mathrm{L})$, as shown in Fig. 2 . Clearly, $\theta_{c}$ changes significantly with various processing steps suggesting different wettabilities. The bare surface only with polished $(\mathrm{P})$ treatment exhibits hydrophilicity with a $\theta_{c}$ of about $32.6^{\circ}$. After modification treatment of the polished sample (P-F), a largely increased $\theta_{c}$ of about $101.9^{\circ}$ is observed. By contrasting the $\theta_{c}$ values on Al-Mg alloys surfaces processed with P-E-F $\left(149.6^{\circ}\right)$, P-B-F $\left(129.5^{\circ}\right)$ and P-E-B-F steps $\left(160.5^{\circ}\right.$ along with a low sliding angle of $\left.5.1^{\circ}\right)$, it is found that the binary hierarchical micro/nanostructures can gain the optimal surface wettability, followed by microstructures, and finally nanostructures. In fact, the prepared structures on various scales show different wettabilities, which might be accounted for the trapped air in the corresponding structures. Fig. 3 depicts the schematic models of the contacting interfaces between the deionized water, air and substrate processed with $\mathrm{P}$ (Fig. 3a1), P-E-F (Fig. 3b1), P-B-F (Fig. 3c1) and P-E-B-F (Fig. 3d1) steps. As exhibited in Fig. 3a1, water can evenly spread out the whole surface only with polishing treatment indicating a complete solid-liquid contacting interface. While, for the alloys surfaces processed with P-E-F, P-B-F and P-E-B-F steps, the prepared rough structures can make the fluctuation morphologies for the covered modified fluorinated films, which can trap air when contacting with water resulting in a newly-presented surface contacting state of the solid-air-liquid. According to Cassie-Baxter [34], a composite solid-air-liquid interface on wetting surface is illustrated in equation (1):

$r=\frac{\cos \theta-\cos \theta_{c}}{1+\cos \theta}$

where $\theta$ is corresponding to the intrinsic $\theta_{c}$ of $101.9^{\circ}$ for the modified bare sample and $r$ is the 
contacting fraction of a droplet only with air. The equation indicates that with P-E-B-F processing, the highest superhydrophobic $\theta_{c}$ of $160.5^{\circ}$ is achieved implying a droplet $92.8 \%$ contacting with air while leaving the rest $7.2 \%$ with substrate, which looks like a spheriform droplet standing on the prepared surface. While, for the surfaces with P-E-F and P-B-F processings, a decreased $r$ is found respectively with $82.7 \%$ and $54.2 \%$ suggesting the binary micro/nanostructures can trap the most air, followed by the microstructures and then nanostructures, which coincides with the above wettabilities of the corresponding prepared surfaces. Meanwhile, three-dimensional profiles of the processed surfaces with P (Fig. 3a2), P-E-F (Fig. 3b2), P-B-F (Fig. 3c2) and P-E-B-F (Fig. 3d2) steps are also shown in Fig. 3. Clearly, the first surface without trapped air produces the lowest average roughness ( $\mathrm{Ra}, 0.2$ $\mu \mathrm{m})$ due to the polishing treatment. An increased average roughness respectively with $1.1,2.1$ and $2.3 \mu \mathrm{m}$ are found for other three surfaces in sequence suggesting the gradually rougher structures to trap more and more air, which is consistent with the best wettability on P-E-B-F processing surface.

As previously demonstrated, an improved wettability on Al-Mg alloys surfaces is attained by preparing the binary hetero-hierarchical micro/nanostructures with P-E-B processing, as shown in Fig. 4a. Fig. 4b and $\mathbf{c}$ respectively describes the elemental composition and distribution analyzed by EDX spectrum and elemental mapping recorded from FESEM image. Clearly, the uniformly covered elements of $\mathrm{O}, \mathrm{Al}$ accompanying with a small quantity of $\mathrm{Mg}$ from the inherent compositions of Al-Mg alloy are seen after P-E-B processing. Meanwhile, FTIR in Fig. 5 has been applied to further investigate the chemical compositions of the modified P-E-B processed surface. Clearly, the absorption bands at 912 and $1079 \mathrm{~cm}^{-1}$ can be respectively assigned to $\mathrm{Si}-\mathrm{C}$ and $\mathrm{Si}-\mathrm{O}-\mathrm{Si}$ stretching vibration bonds. The bands appearing at around 1244 
and $779 \mathrm{~cm}^{-1}$ are due to the stretching vibrations of C-F bonds confirming that the fluoro groups with low surface energy have been introduced on surface resulting in an enhanced wettability. The strong adsorption band at about $2942 \mathrm{~cm}^{-1}$ is identified as C-H stretching vibration bond in the modified coating, which can achieve a good ability of anti-OH bonds suggesting a further intensified repelling ability to liquids. All these indicate that the fluoroalkyl-silane film has been successfully introduced on P-E-B processed surface to attain a better wettability.

The $\theta_{c}$ of a water droplet on P-E-B-F processed surface versus etching time in $\mathrm{HCl}$ solution at different temperatures of $5{ }^{\circ} \mathrm{C}, 20{ }^{\circ} \mathrm{C}$ and $35^{\circ} \mathrm{C}$ (respectively corresponding to room temperatures of winter, spring or autumn, and summer of Central China) managed in temperature-controlled water baths is presented in Fig. 6a. As previously shown, the P-B-F processed surface without acid etching just emerges with an average hydrophobic $\theta_{c}$ of $129.5^{\circ}$ $\left(5^{\circ} \mathrm{C}\right)$. As seen in Fig. 6a, $\theta_{c}$ sustainably increases to $130.1^{\circ}, 135.3^{\circ}, 142.5^{\circ}$ and $157.4^{\circ}$ after sample being immersed into etchant respectively for 2, 6, 10 and $14 \mathrm{~min}$, which might be accounted for the gradually formed etched roughly hierarchical labyrinth-like tridimensional structures, as shown in Fig. S1 of the Supporting Information. With the immersing time extending to 18 min, a surface with the exactly formed binary micro/nanostructures in Fig. S1 is demonstrated with the hightest superhydrophobic $\theta_{c}$ of $160.5^{\circ}$. Then $\theta_{c}$ remains almost constant with a longer etching time. With the experimental temperatures increasing to $20{ }^{\circ} \mathrm{C}$ and $35^{\circ} \mathrm{C}$, the maximal average $\theta_{c}$ are achieved more in advance with about $12 \mathrm{~min}$ and 6 min, respectively. According to the Arrhenius equation, reaction rate can accelerate with the increased environmental temperature, which accounts for the above shortened etching time. Moreover, the $\theta_{c}$ of a water droplet on P-E-B-F processed alloys surfaces with different 
immersion time in boiling deionized water is investigated in Fig. 6b. Obviously, $\theta_{c}$ on the etched surface after being modified without boiling processing is about $149.6^{\circ}$. Then a rapidly increased $\theta_{c}$ is seen with the prolonging immersion time. With the boiling time extending to 10 $\mathrm{s}$, a superhydrophobic $\theta_{c}$ of $151.8^{\circ}$ is attained. While $\theta_{c}$ can achieve the maximal value of $160.5^{\circ}$ after being treated for $60 \mathrm{~s}$. After that, $\theta_{c}$ also remains almost constant with a longer immersion time for the already formed twisty nanoflakes. Based on the above analysis, it is further concluded that the etching microstructures accompanying with boiling nanostructures can exert an active effect on the wettability of the prepared Al-Mg alloys surfaces.

In order to further confirm the superoleophobicity of the substrate surface processed with P-E-B-F steps, the optical images $(25 \mu \mathrm{L})$ and the corresponding contact angle measurements $(5 \mu \mathrm{L})$ of water, glycerol, rapeseed oil and hexadecane droplets on prepared surface are investigated in Fig. 7a. It is clearly seen that all droplets exhibit approximately spherical shapes. Meanwhile, $\theta_{c}$ with $160.5^{\circ}, 151.4^{\circ}, 154.1^{\circ}$ and $156.8^{\circ}$ is respectively found for water, hexadecane, rapeseed oil and glycerol droplets suggesting superior superoleophobicity. Tuteja et al. have described that by fabricating the overhanging geometries and some reentrant curvature structures on substrate can bring about excellent superoleophobicity. Such features can effectively contribute to the formation of multiple solid-air-oil interface, which can stop oil droplets from penetrating in their cavity structures [35]. In this work, the typical oil droplets obtain $\theta_{c}$ higher than $150^{\circ}$ suggesting the fabricated hierarchical binary micro/nanostructures can exactly provide the particular features required for excellent repelling behavior to oil droplets. Generally, a superoleophobic surface is identified not only with a $\theta_{c}$ higher than $150^{\circ}$, but also with low adhesion characteristics to substrate surface. Fig. $\mathbf{7 b}$ depicts a test about adhesion characteristics between a rapeseed oil droplet $(5 \mu \mathrm{L})$ and the P-E-B-F processed 
surface by making different contacting states. In the course of the whole experiment, the prepared substrate just keeps towards (Fig. 7b1-b4) or away (Fig. 7b4-b6) from the droplet adsorbed on a fixed syringe needle. As is clearly seen, the droplet gradually raise with the rising substrate but without fleeing the needle. After breaking away from the substrate, the droplet still keeps contacting with the needle without oil residues existing on substrate surface. Therefore, the adhesive performance between the oil droplet and the P-E-B-F processed surface is quietly weak. As a consequence, the superamphiphobic Al-Mg alloys surfaces have been successfully achieved with a simple and low-cost P-E-B-F processing.

\subsection{Anticorrosion behavior measurements}

Anticorrosion behaviors of Al-Mg alloys samples processed with P, P-F, P-E-F, P-B-F and P-E-B-F steps are investigated by EIS in $3.5 \mathrm{wt} \%$ seawater. And also the corresponding Nyquist plot and its partial enlarged details are respectively shown in Fig. 8a and Fig. 8b. Clearly, a capacitive arc is seen for all the processed surfaces in addition to the varied capacitive arc sizes relating to the charge transfer capacity between alloys samples and electrolyte in corrosive course. Generally, a large capacitive arc size is corresponding to an improved polarization resistance suggesting a better inhibiting ability of electron transfer and a superior anticorrosion behavior [36]. As seen, after the bare polished sample being modified, a larger capacitive arc is observed. Meanwhile, the capacitive arc size for P-E-F and P-B-F steps is respectively about 2 and 1.5 times larger than that of P-F processed sample. When it comes to the P-E-B-F steps with hierarchical micro/nanostructures, the largest capacitive arc is found among all surfaces demonstrating the optimal anticorrosion behavior. In fact, affected by the trapped air in prepared structures, binary micro/nanostructures can attain the optimal repelling ability to corrosive medium, followed by microstructures, and finally nanostructures. Hence, 
the binary structures with P-E-B-F steps posing the least contacting fraction with a droplet of corrosive medium can certainly show the optimal anticorrosion behavior, followed by P-E-F steps, and then P-B-F steps. Furthermore, the impedance module (Z) of Bode plots in Fig. 8c for the alloy surface processed with different steps varies from one another at the whole tested frequency. Obviously, the variation trend of the above impedance module is in accord with the capacitive arc size further confirming the optimal anticorrosion behavior of the P-E-B-F processed surface. Besides, only one time constant at about $100 \mathrm{HZ}$ in the phase angle of Bode plots for bare polished surface is found in Fig. 8d, which is in relation to electrochemical activation of the polished surface in seawater and attributed to the electric double-layer capacitance at the interface between electrolyte and substrate [37]. While for other modified surfaces, two time constants including a high frequency (about $100 \mathrm{HZ})$ and low frequency (< $0.1 \mathrm{~Hz}$ ) are seen, which is respectively associated with the modified films on Al-Mg alloys surfaces and the electric double-layer capacitance at the interface between electrolyte and substrate. It is noteworthy that the time constant at low frequency of the modified surfaces $(<$ $0.1 \mathrm{~Hz}$ ) is lower than the bare polished one without modification (about $100 \mathrm{HZ}$ ) demonstrating an improved isolation effect to seawater for modified surfaces [37].

To accurately analyze the electrochemical impedance data and corrosion resistance mechanism of the processed surfaces in seawater, the electrochemical fittings with equivalent circuit patterns for the bare polished sample and modified samples are investigated. After a sequence of fittings with ZSimDemo software, the equivalent circuit pattern in Fig. 9a is found to be appropriate to match the corrosion process of the bare polished sample. And also CPE1 and $\mathrm{R}_{\mathrm{ct} 1}$ respectively denotes the double layer capacitance and charge transfer resistance at the substrate/electrolyte interface in this pattern, among which the electrochemical corrosion can 
start comprehensively at the whole polished sample surface, as distinctly illustrated in corrosion mechanism diagram of Fig. S2a in the Supporting Information. Fig. 9b shows the equivalent circuit pattern for the modified coatings, among which $R_{c}$ and CPE2 is respectively corresponding to the resistance and capacitance of the modified coating. $R_{s}$ represents the electrolyte resistance in both of the circuits. While, $\mathrm{C}_{\mathrm{d} 1}$ and $\mathrm{R}_{\mathrm{ct} 2}$ respectively refers to double layer capacitance and charge transfer resistance existing at the substrate/coating interface of a local corroded region. As a matter of fact, even for a well sealed modification coating, there must be some millipores existing in coatings allowing the corrosive chlorine ions in seawater penetrating through the modified coating to form a tiny local corrosion region. Such corrosion mechanism as well as the millipores of the tiny local corrosion section can be demonstrated in

\section{Fig. S2b of the Supporting Information.}

After electrochemical fittings with the above two equivalent circuit patterns, the circuit components parameters with different processed samples have been presented in Table 1. Clearly, a gradually increased $\mathrm{R}_{\mathrm{ct}}$ is observed for samples successively processed with $\mathrm{P}, \mathrm{P}-\mathrm{F}$, P-B-F, P-E-F and P-E-B-F steps suggesting an improved ability of resisting charge transfer between seawater and substrate namely an improved electrochemical corrosion inhibition effect, which is consistent with the results of electrochemical impedance spectroscopy measurements. As shown in the corrosive mechanism of the modified surfaces, the corroded area fraction induced by the millipores of the local corrosion regions is set as $\alpha$ herein, while $\beta$ is assigned to the remaining coverage rate for the modified coating among the whole surface ( $\alpha$ $+\beta=1$ ). The relationship between $\alpha$ and $\mathrm{R}_{\mathrm{ct}}$ is described in the following equation [38]:

$\alpha=\frac{R_{c t 1}}{R_{c t 2}} \times 100 \%$ 
According to equation (2), the coverage rate $\beta$ of the modified coating is calculated in Table 1 . Obviously, $\beta$ value for the P-F processed surface $(67.1 \%)$ is lower than others (> 80\%) suggesting a low coverage rate of the modified coating on surface owing to millipores. For the modified surface processed with P-E-B-F steps, the maximal $\beta$ value of $90.0 \%$ is observed suggesting the highest coverage rate of the modified coating as well as the best anticorrosion ability among all the processed samples. Meanwhile, the fitting plots have been presented in Fig. S3 of the Supporting Information. As seen, the electrochemical fitting data can well match the Nyquist data from electrochemical impedance spectroscopy measurements. Hence, the corrosive data simulated in this work can be further proved to be reasonable. In addition, the potentiodynamic polarization curves of the processed samples in $3.5 \mathrm{wt} \%$ seawater have also been measured to characterize the corrosion resistance in Fig. 10. In general, a positive-shifting corrosion potential $\left(E_{\text {corr }}\right)$ accompanied by a lower corrosion current density $\left(I_{\text {corr }}\right)$ can result in excellent anticorrosion behavior [36]. Evidently, $E_{\text {corr }}$ goes positively from $-1.298,-1.112,-0.958,-0.807$ to $-0.735 \mathrm{~V}$ for the Al-Mg alloys samples processed with P, P-F, P-B-F, P-E-F and P-E-B-F steps in sequence. Meanwhile, Fig. 10 also exhibits a gradually decreased $I_{\text {corr }}$ obtained by the Tafel extrapolation method for the above processed samples respectively with $113.6,2.389,1.622,0.672$ and $0.205 \mu \mathrm{A} . \mathrm{cm}^{-2}$. Such results about corrosion resistance ability with different treatments exactly meet the results in EIS measurements. In all, the corrosion resistance property of P-E-B-F processed substrate is vastly improved with the binary micro/nanostructures for the highest coverage rate of the modified coating. Besides, it is worth mentioning that the corrosion resistance behavior of the processed sample with P-E-B-F steps can be found superior than the ever reported superhydrophobic surfaces on aluminum alloys substrates in Ref [39], [40], [41] and [42] after the comparison of $I_{\text {coor }}$ values. 


\subsection{Analyter concentration and SERS determination tests}

In addition to excellent corrosion resistance behavior, the superamphiphobic surface processed with P-E-B-F steps also presents a perspective in concentrators, which can stop the solution containing toxic and pollutive ions from diffusing. Fig. 11a exhibits the air-dried morphology changes for a water droplet $(25 \mu \mathrm{L})$ containing crystal violet and Au nanoparticles, among which a contracted droplet volume on the prepared surface is clearly observed with its gradual evaporation resulting in an increased analytes concentration, as described in Fig. 11d. For the glass slide, however, a rapidly spread and diffused water droplet containing analytes as well as the corresponding air-dried circle area is found in Fig. 11b. And also it can certainly account for a decreased analytes concentration. Hence, the processed surface can possess a potential application in concentrators to improve the surface-enhanced Raman scattering analysis and detection sensitivity of toxic and pollutive ions. Compared with the glass slide, Fig. 11c shows a distinctly enhanced Raman intensity at a point on the prepared surface after the surface-enhanced Raman scattering measurement of the analytes. Based on the above analysis, the P-E-B-F processed superamphiphobic surface with the binary hierarchical micro/nanostructure can possess a great potential application in the analyte concentration and determination fields, especially for the toxic and pollutive ions.

\section{Conclusions}

A simple and low-cost method was demonstrated to prepare the superhydrophobic and superoleophobic Al-Mg alloys surfaces with improved anticorrosion behavior. The superamphiphobic binary structures with labyrinth-like concave-convex microstructures and twisty nanoflakes were achieved by the successively polishing, etching and boiling treatments. 
After fluoroalkyl-silane modification of the as-prepared structures, a surface with superior repelling ability to water, glycerol, rapeseed oil and hexadecane was finally confirmed. It was accounted for the trapped air in prepared structures generating newly-presented substrate-air-liquid contacting interface to isolate alloys substrates from liquids. Meanwhile, the enhanced anticorrosion behavior of the as-prepared surfaces in seawater was electrochemically assessed. The corrosion process of the modified surfaces in seawater was believed to be achieved by the millipores in coating resulting in the local corroded channels for seawater penetration. Nevertheless, the hierarchical micro/nanostructures accompanying with the modified coating could possess the maximal coating coverage rate as well as the optimal anticorrosion behavior, followed by microstructures, then nanostructures and finally bare polished surface. Furthermore, the superamphiphobic surface was proved to possess a great potential application in concentrators for SERS analysis of toxic and pollutive ions.

\section{Acknowledgements}

This work is supported by the financial support of the National Science Foundation of China (51174151). Authors thank Dr. X.D. Wang for his contribution in the characterization of FESEM images and three-dimensional noncontact surface profiles.

\section{References}

[1] B. Xiao, D.P. Wang, F.J. Cheng, Y. Wang, Appl. Surf. Sci. 337 (2015) 208.

[2] B.H. Lee, S.H. Kim, J.H. Park, H.W. Kim, J.C. Lee, Mat. Sci. Eng. A-Struct. 657 (2016) 115.

[3] S.H. Yan, Y. Nie, Z.T. Zhu, H. Chen, G.Q. Gou, J.P. Yu, G.G. Wang, Appl. Surf. Sci. 298 (2014) 12. 
[4] N.Q. Tuan, A.C. Alves, F. Toptan, A.B. Lopes, A.M.P. Pinto, Mater. Corros. 67 (2016) 60.

[5] B. Zou, Z.Q. Chen, C.H. Liu, J.H. Chen, Appl. Surf. Sci. 296 (2014) 154.

[6] S.H. Park, J.S. Kim, M.S. Han, S.J. Kim, T. Nonferr. Metal. Soc. 19 (2009) 898.

[7] W.J. Golumbfskie, K.T. Tran, J.M. Noland, R. Park, D.J. Stiles, G. Grogan, C. Wong, Corrosion 72 (2016) 314.

[8] L. Guan, Y. Zhou, B. Zhang, J.Q. Wang, E.H. Han, W. Ke, Corros. Sci. 103 (2016) 255.

[9] B. Wang, J. Liu, M. Yin, Y. Xiao, X.H. Wang, J.X. He, Mater. Corros. 67 (2016) 51.

[10] X. Shu, Y.X. Wang, X. Lu, C.M. Liu, W. Gao, Surf. Coat. Tech. 276 (2015) 195.

[11] S.M. Li, Y.D. Li, Y. Zhang, J.H. Liu, M. Yu, Int. J. Min. Met. Mater. 22 (2015) 167.

[12] J.Y. Wang, C. Li, S.L. Zheng, C.Y. Yin, Y.H. Wang, T. Nonferr. Metal. Soc. 24 (2014) 3023.

[13] M.N. Ibarra, J.M. Almanza, D.A. Cortes, J.C. Escobedo, M. Pech, R. Martinez, J. Eur. Ceram. Soc. 35 (2015) 2189.

[14] A. Alil, M. Popovic, T. Radetic, M. Zrilic, E. Romhanji, J. Alloy. Compd. 625 (2015) 76.

[15] F. Jiang, J. Zhou, H. Huang, J. Qu, Mater. Res. Innov. 18 (2014) 228.

[16] J. Seong, G.S. Frankel, N. Sridhar, Corrosion 72 (2016) 284.

[17] J. Seong, G.S. Frankel, N. Sridhar, J. Electrochem. Soc. 162 (2015) C449.

[18] S. Rasouli, R.A. Behnagh, A. Dadvand, N. Saleki-Haselghoubi, P.I. Mech. Eng. L-J. Mat. 230 (2016) 142.

[19] N. Zazi, J.P. Chopart, A. Bouabdallah, Prot. Met. Phys. Chem. 51 (2015) 267.

[20] U. Trdan, M. Skarba, J. Grum, Mater. Charact. 97 (2014) 57.

[21] S.G. Lovineh, M. Asghari, G. Khanbabaei, Appl. Surf. Sci. 318 (2014) 176.

[22] C. Borsoi, A.J. Zattera, C.A. Ferreira, Appl. Surf. Sci. 364 (2016) 124. 
[23] S.Y. Chen, S.T. Zhang, X.L. Ren, S.Y. Xu, L.L. Yin, Int. J. Electrochem. Sc. 10 (2015) 9073.

[24] A. Sengupta, S.N. Malik, D. Bahadur, Appl. Surf. Sci. 363 (2016) 346.

[25] L.P. Kazansky, Y.I. Kuznetsov, N.P. Andreeva, Y.G. Bober, Appl. Surf. Sci. 364 (2016) 124.

[26] H.D. Yu, Z.X. Lian, Y.L. Wan, Z.K. Weng, J.K. Xu, Z.J. Yu, Surf. Coat. Tech. 275 (2015) 112.

[27] Y. Liu, J.J. Zhang, S.Y. Li, Y.M. Wang, Z.W. Han, L.Q. Ren, RSC Adv. 4 (2014) 45389.

[28] M.K. Tang, X.J. Huang, Z. Guo, J.G. Yu, X.W. Li, Q.X. Zhang, Colloid. Surface. A 484 (2015) 449.

[29] Y.H. Wu, W.J. Zhao, W.R. Wang, W.J. Sui, RSC Adv. 6 (2016) 5100.

[30] J.W. Lee, W. Hwang, Mater. Lett. 168 (2016) 83.

[31] Y. Huang, D.K. Sarkar, X.G. Chen, Appl. Surf. Sci. 356 (2015) 1012.

[32] L.J. Li, T. Huang, J.L. Lei, J.X. He, L.F. Qu, P.L. Huang, W. Zhou, N.B. Li, F.S. Pan, ACS Appl. Mater. Inter. 7 (2015) 1449.

[33] A. Motta, O. Cannelli, A. Boccia, R. Zanoni, M. Raimondo, A. Caldarelli, F. Veronesi, ACS Appl. Mater. Inter. 7 (2015) 19941.

[34] A.B.D. Cassie, S. Baxter, Trans. Faraday Soc. 40 (1944) 546.

[35] A. Tuteja, W. Choi, M. Ma, J.M. Mabry, S.A. Mazzella, G.C. Rutledge, G.H. McKinley, R.E. Cohen, Science 318 (2007) 1618.

[36] Y.S. Yin, T. Liu, S.G. Chen, T. Liu, S. Cheng, Appl. Surf. Sci. 255 (2008) 2978.

[37] D. Yu, J. Tian, J. Dai, X. Wang, Electrochim. Acta 97 (2013) 409.

[38] P. Wang, D. Zhang, R. Qiu, Corros. Sci. 54 (2012) 77. 
[39] Y.Y. Cheng, S.X. Lu, W.G. Xu, RSC Adv. 39 (2015) 6602.

[40] R.G. Wankhede, S. Morey, A.S. Khanna, N. Birbilis, Appl. Surf. Sci. 283 (2013) 1051.

[41]L.B. Feng, Z.N. Yan, X.H. Qiang, Y.P. Wang, Y.H. Liu, Surf. Interface Anal. 47 (2015) 506.

[42]D.M. Lv, J.F. Ou, M.S. Xue, F.J. Wang, Appl. Surf. Sci. 333 (2015) 163. 


\section{Figure Captions}

Fig. 1. Low and high-magnified FESEM images of Al-Mg alloys surfaces after being polished (a1-a3) and then immersed into boiling deionized water for $60 \mathrm{~s}$ (b1-b3). Low and high-magnified FESEM images of the polished alloys surfaces after being immersed into $\mathrm{HCl}$ solution for $18 \mathrm{~min}(\mathrm{c} 1-\mathrm{c} 2)$ and then boiling deionized water for $60 \mathrm{~s}$ (d1-d2).

Fig. 2. Static water contact angle $(5 \mu \mathrm{L})$ on prepared $\mathrm{Al}-\mathrm{Mg}$ alloys surfaces with $\mathrm{P}$ processing (polish), P-F processing (polish then modify), P-E-F processing (polish, etch then modify), P-B-F processing (polish, boil then modify) and P-E-B-F processing (polish, etch, boil then modify). The snapshot at top-left corner referring to the sliding angle measurement of a water droplet on superhydrophobic surface processed with P-E-B-F steps.

Fig. 3. Schematic model of the contacting interface between deionized water, air and $\mathrm{Al}-\mathrm{Mg}$ alloys substrates processed with P (a1), P-E-F (b1), P-B-F (c1) and P-E-B-F steps (d1). (a2-d2) corresponding to the three-dimensional profiles of the processed surfaces respectively with $\mathrm{P}$, P-E-F, P-B-F and P-E-B-F steps.

Fig. 4. FESEM image (a) of roughly hierarchical labyrinth-like concave-convex structures covered with twisty nanoflakes processed with P-E-B steps. EDX spectrum (b) and Al, Mg and O elemental mapping (c) recorded from FESEM image (a).

Fig. 5. FTIR spectrum of superhydrophobic Al-Mg alloys surfaces with polishing, etching, 
boiling and modifying processing. The insert corresponding to photograph of a water droplet $(25 \mu \mathrm{L})$ dripping on the as-prepared surface.

Fig. 6. The contact angles of a water droplet on Al-Mg alloys surfaces processed with P-E-B-F steps versus etching time at different temperatures managed in temperature-controlled water baths (a). The contact angles of a water droplet on Al-Mg alloys surfaces processed with P-E-B-F steps as a function of boiling time in deionized water (b).

Fig. 7. Optical images $(25 \mu \mathrm{L})$ and contact angle measurements $(5 \mu \mathrm{L})$ of water, hexadecane, rapeseed oil and glycerol droplets on Al-Mg alloys surfaces with P-E-B-F processing (a). Adhesive behavior test between a rapeseed oil droplet $(5 \mu \mathrm{L})$ and sample with P-E-B-F processing by making different contacting states (b).

Fig. 8. Nyquist plot (a) as well as the corresponding partial enlarged details (b), Bode plots (c-d) from electrochemical impedance spectroscopy measurements of the processed surfaces with different steps in $3.5 \mathrm{wt} \%$ seawater.

Fig. 9. Equivalent circuit patterns for the bare polished sample (a) and modified samples with P-F, P-E-F, P-B-F, P-E-B-F processings (b). CPE1 and $\mathrm{R}_{\mathrm{ct} 1}$ respectively denoting the double layer capacitance and charge transfer resistance at the substrate/electrolyte interface, $R_{c}$ and CPE2 respectively corresponding to the resistance and capacitance of the modified coating, $\mathrm{C}_{\mathrm{dl}}$ and $\mathrm{R}_{\mathrm{ct} 2}$ respectively referring to double layer capacitance and charge transfer resistance existing at the substrate/coating interface of a local corroded region, $\mathrm{R}_{\mathrm{s}}$ representing the 
electrolyte resistance.

Fig. 10. Potentiodynamic polarization curves of samples processed with P, P-F, P-E-F, P-B-F, P-E-B-F steps in $3.5 \mathrm{wt} \%$ seawater.

Fig. 11. Optical images of the air-dried morphology changes for a water droplet $(25 \mu \mathrm{L})$ containing crystal violet and Au nanoparticles on Al-Mg alloys surface processed with P-E-B-F steps (a) and the glass slide (b). (c) referring to the surface-enhanced Raman scattering analysis and detection of the analytes at a random selected point on the dried areas of (a2) and (b2). (d) corresponding to the schematic process of a droplet evaporation on the fabricated superamphiphobic surface.

\section{Table Captions}

Table 1. The equivalent circrsuit components parameters after electrochemical fittings. 

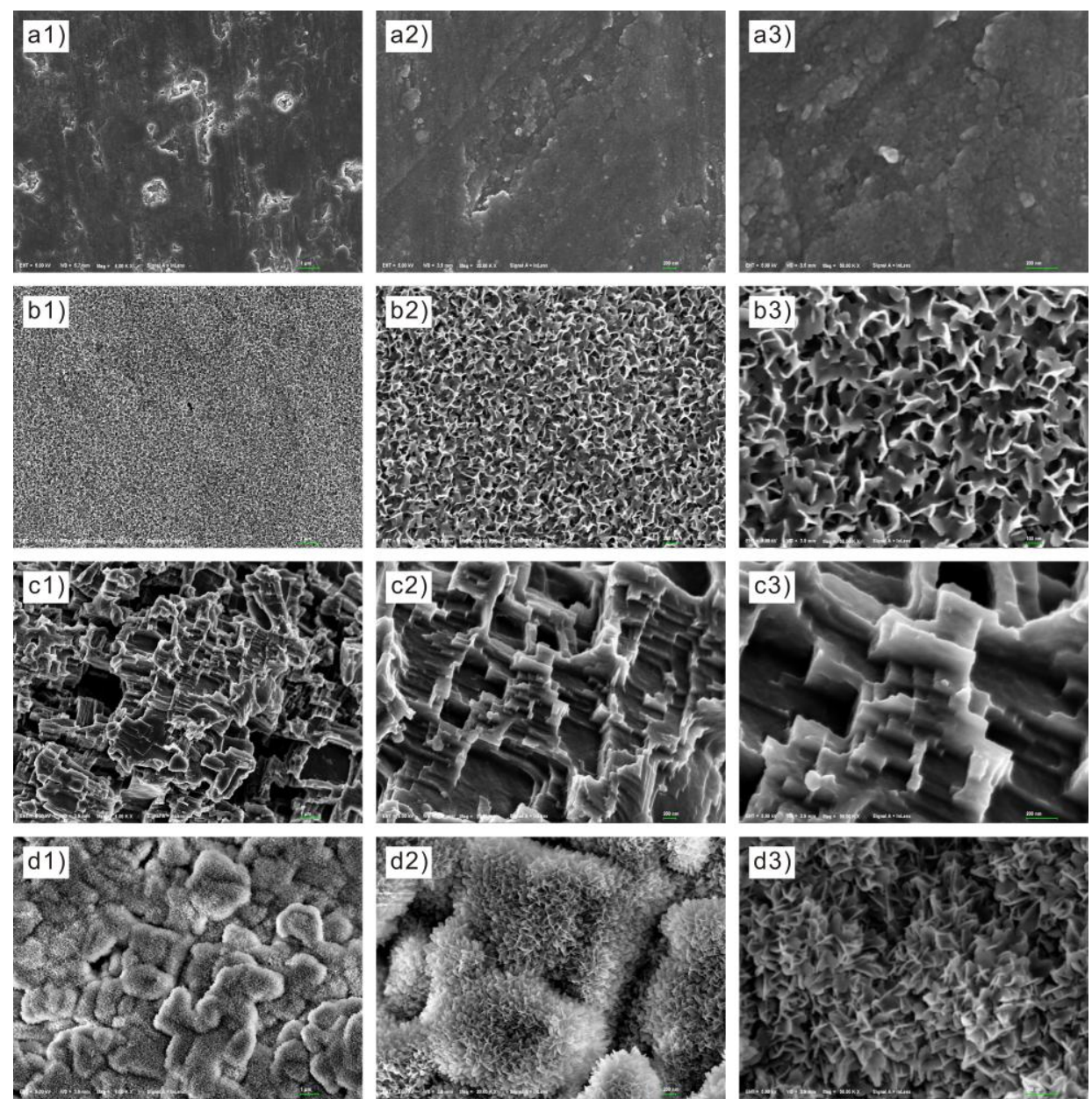

Fig. 1. Low and high-magnified FESEM images of Al-Mg alloys surfaces after being polished (a1-a3) and then immersed into boiling deionized water for $60 \mathrm{~s}$ (b1-b3). Low and high-magnified FESEM images of the polished alloys surfaces after being immersed into $\mathrm{HCl}$ solution for $18 \mathrm{~min}(\mathrm{c} 1-\mathrm{c} 2)$ and then boiling deionized water for $60 \mathrm{~s}(\mathrm{~d} 1-\mathrm{d} 2)$. 


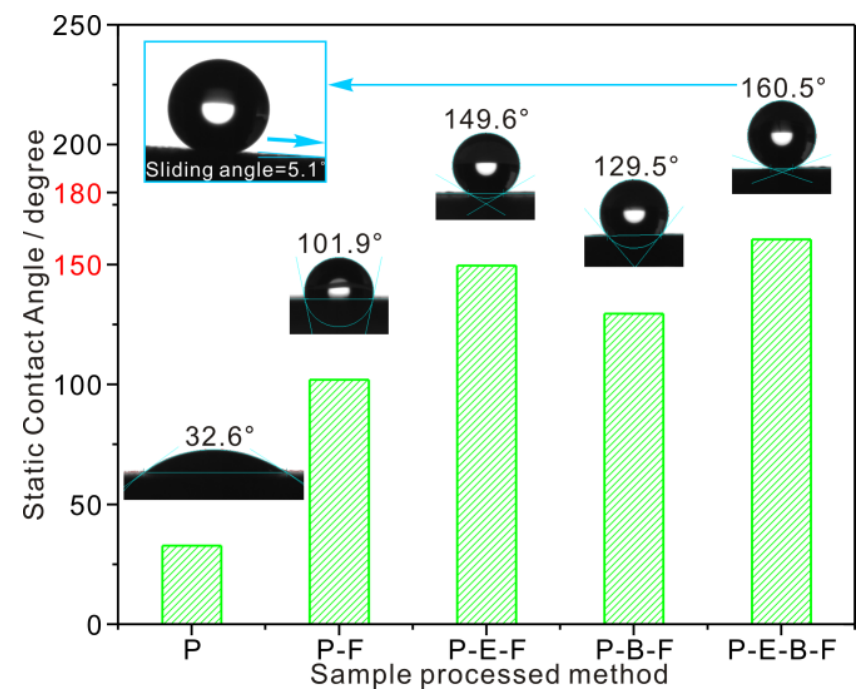

Fig. 2. Static water contact angle $(5 \mu \mathrm{L})$ on prepared Al-Mg alloys surfaces with $\mathrm{P}$ processing (polish), P-F processing (polish then modify), P-E-F processing (polish, etch then modify), P-B-F processing (polish, boil then modify) and P-E-B-F processing (polish, etch, boil then modify). The snapshot at top-left corner referring to the sliding angle measurement of a water droplet on superhydrophobic surface processed with P-E-B-F steps. 

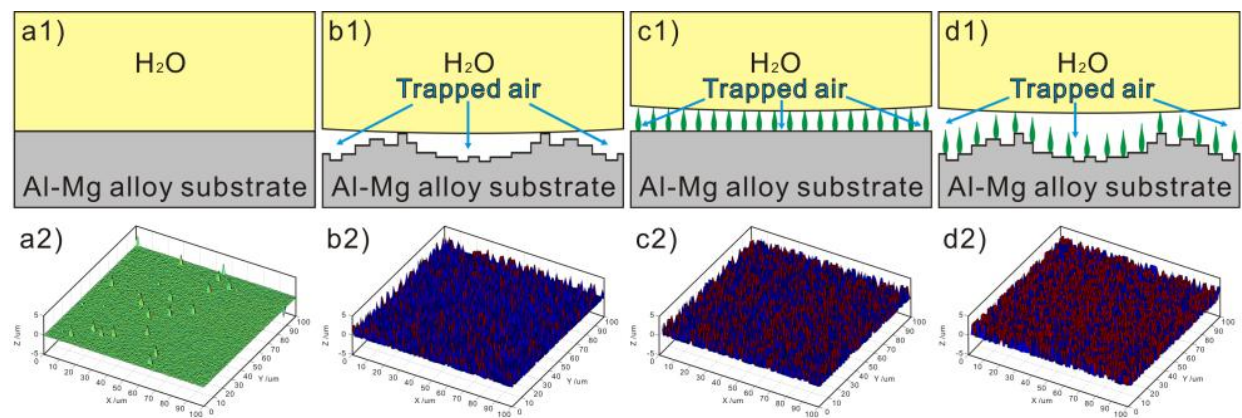

Fig. 3. Schematic model of the contacting interface between deionized water, air and $\mathrm{Al}-\mathrm{Mg}$ alloys substrates processed with P (a1), P-E-F (b1), P-B-F (c1) and P-E-B-F steps (d1). (a2-d2) corresponding to the three-dimensional profiles of the processed surfaces respectively with $\mathrm{P}$, P-E-F, P-B-F and P-E-B-F steps. 


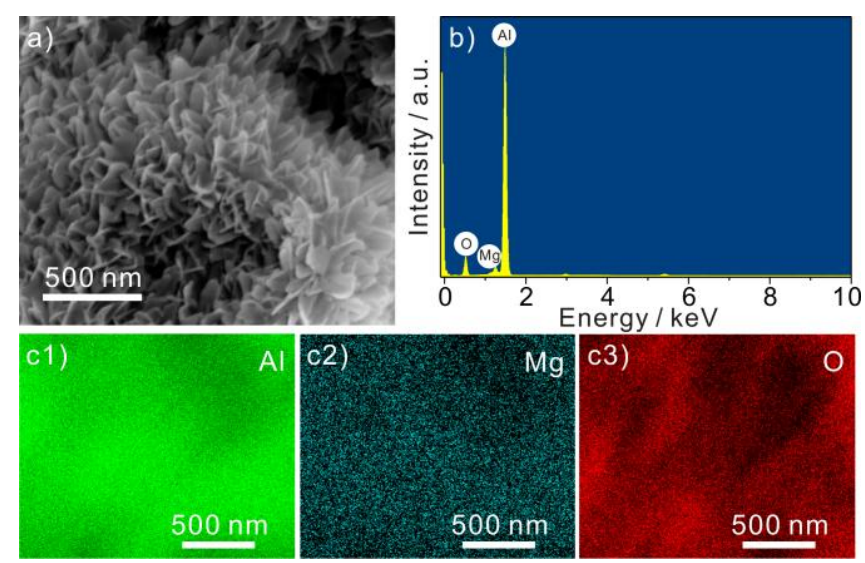

Fig. 4. FESEM image (a) of roughly hierarchical labyrinth-like concave-convex structures covered with twisty nanoflakes processed with P-E-B steps. EDX spectrum (b) and Al, Mg and O elemental mapping (c) recorded from FESEM image (a). 


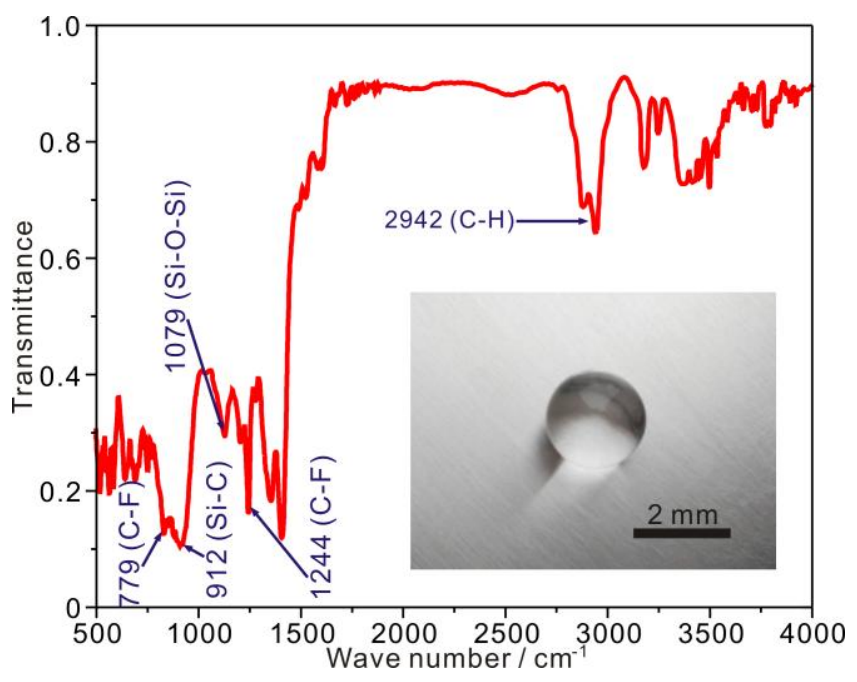

Fig. 5. FTIR spectrum of superhydrophobic Al-Mg alloys surfaces with polishing, etching, boiling and modifying processing. The insert corresponding to photograph of a water droplet (25 $\mu \mathrm{L}$ ) dripping on the as-prepared surface. 

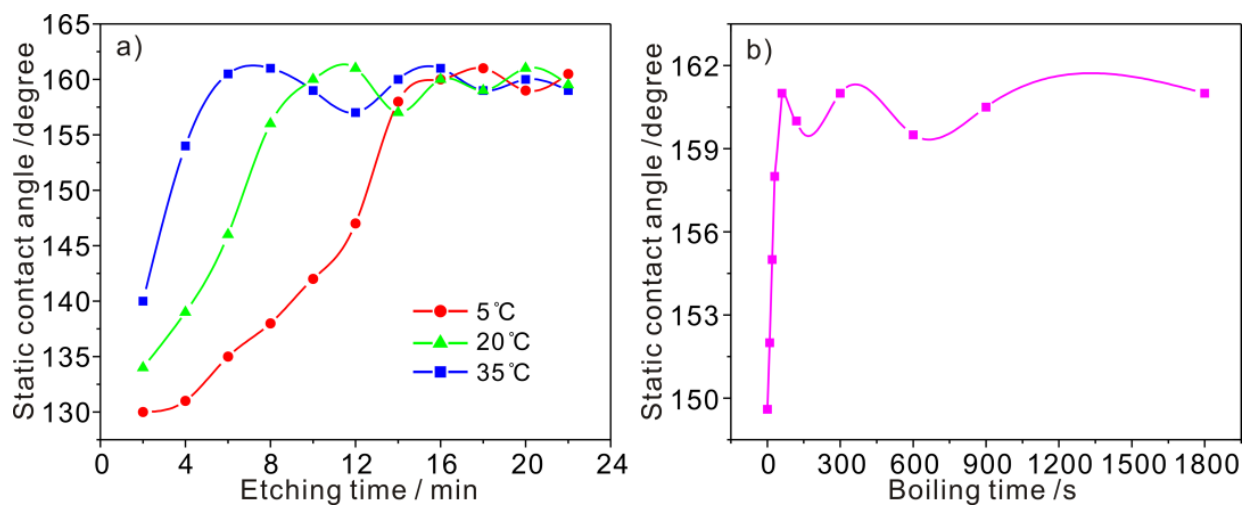

Fig. 6. The contact angles of a water droplet on Al-Mg alloys surfaces processed with P-E-B-F steps versus etching time at different temperatures managed in temperature-controlled water baths (a). The contact angles of a water droplet on Al-Mg alloys surfaces processed with P-E-B-F steps as a function of boiling time in deionized water (b). 


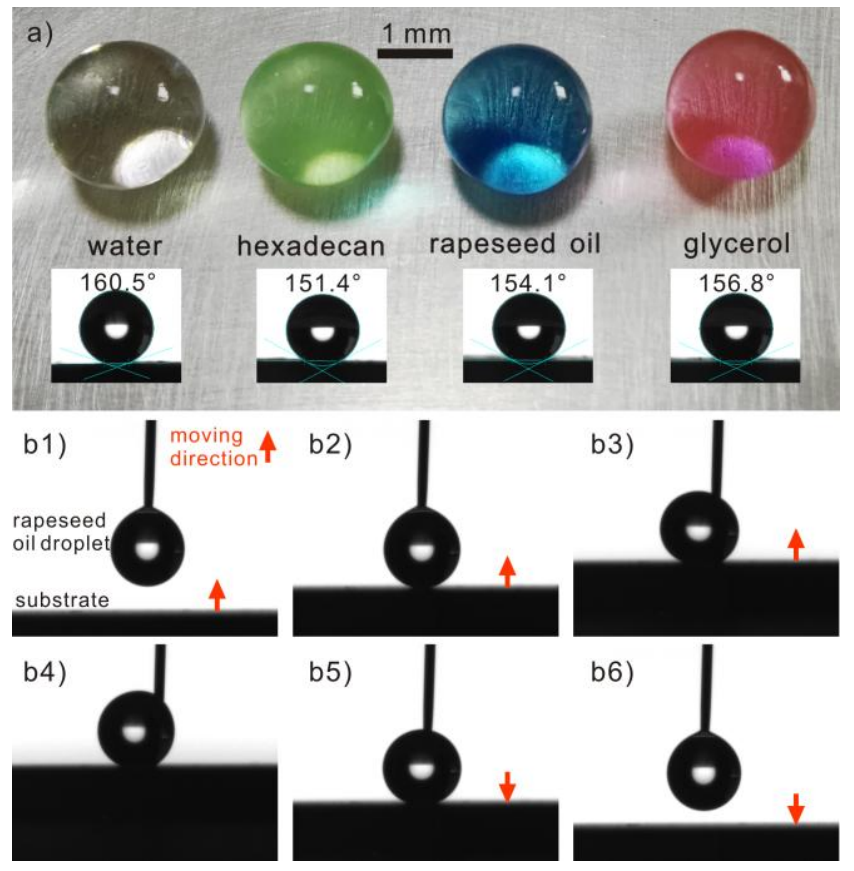

Fig. 7. Optical images $(25 \mu \mathrm{L})$ and contact angle measurements $(5 \mu \mathrm{L})$ of water, hexadecane, rapeseed oil and glycerol droplets on Al-Mg alloys surfaces with P-E-B-F processing (a). Adhesive behavior test between a rapeseed oil droplet $(5 \mu \mathrm{L})$ and sample with P-E-B-F processing by making different contacting states (b). 

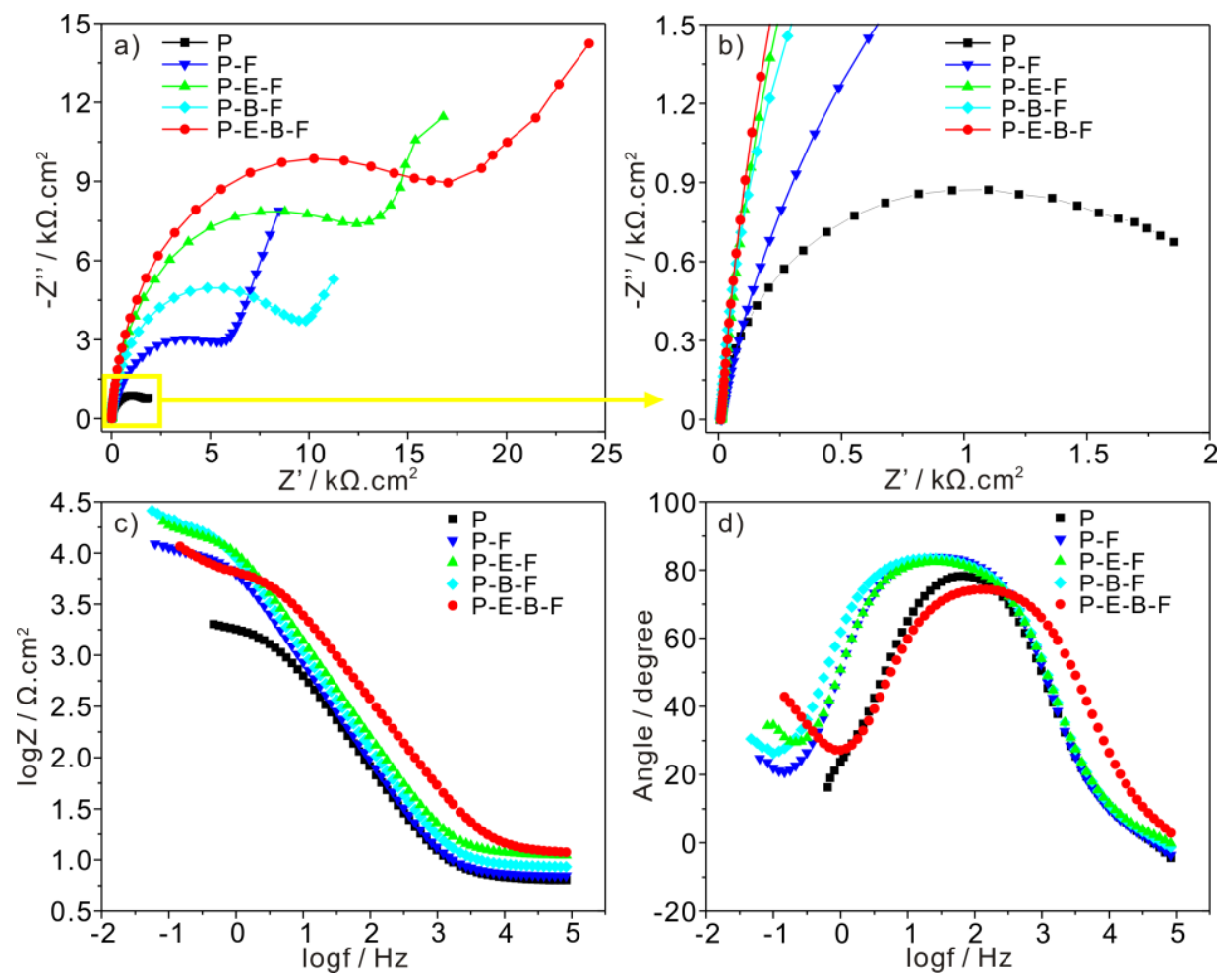

Fig. 8. Nyquist plot (a) as well as the corresponding partial enlarged details (b), Bode plots (c-d) from electrochemical impedance spectroscopy measurements of the processed surfaces with different steps in $3.5 \mathrm{wt} \%$ seawater. 


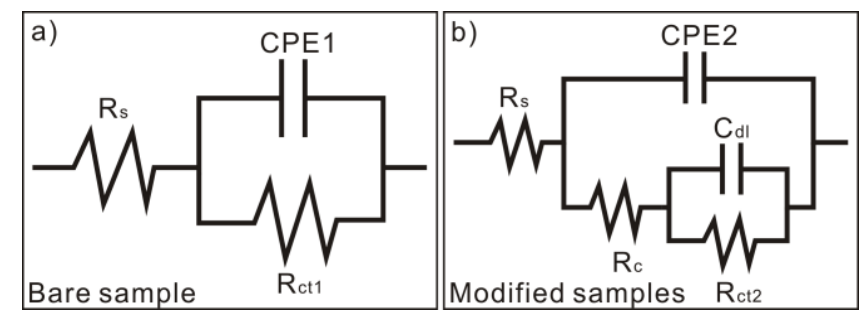

Fig. 9. Equivalent circuit patterns for the bare polished sample (a) and modified samples with P-F, P-E-F, P-B-F, P-E-B-F processings (b). CPE1 and $\mathrm{R}_{\mathrm{ct} 1}$ respectively denoting the double layer capacitance and charge transfer resistance at the substrate/electrolyte interface, $R_{c}$ and CPE2 respectively corresponding to the resistance and capacitance of the modified coating, $\mathrm{C}_{\mathrm{dl}}$ and $R_{\mathrm{ct} 2}$ respectively referring to double layer capacitance and charge transfer resistance existing at the substrate/coating interface of a local corroded region, $\mathrm{R}_{\mathrm{s}}$ representing the electrolyte resistance. 


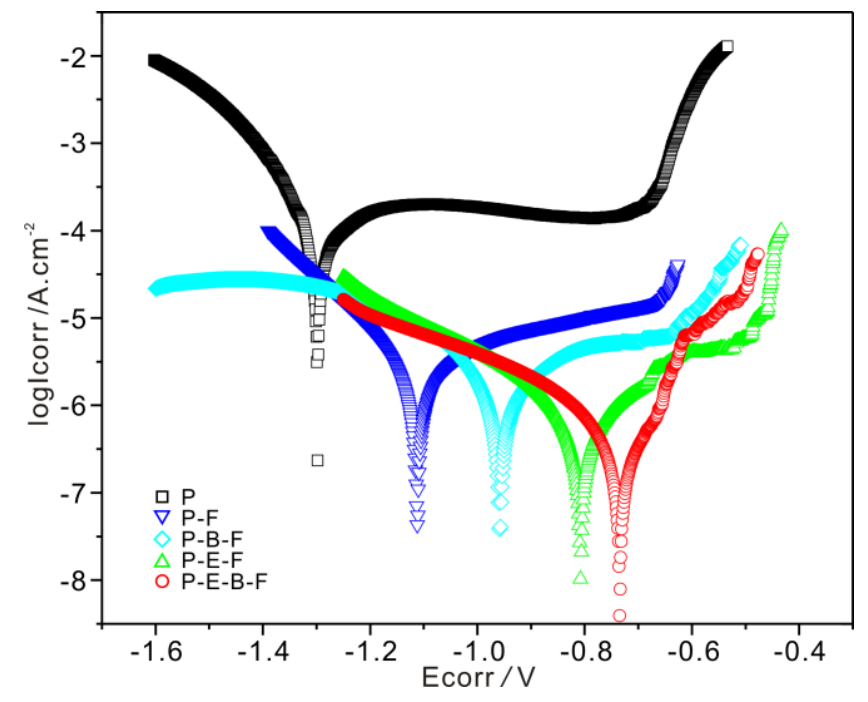

Fig. 10. Potentiodynamic polarization curves of samples processed with P, P-F, P-E-F, P-B-F, P-E-B-F steps in $3.5 \mathrm{wt} \%$ seawater. 


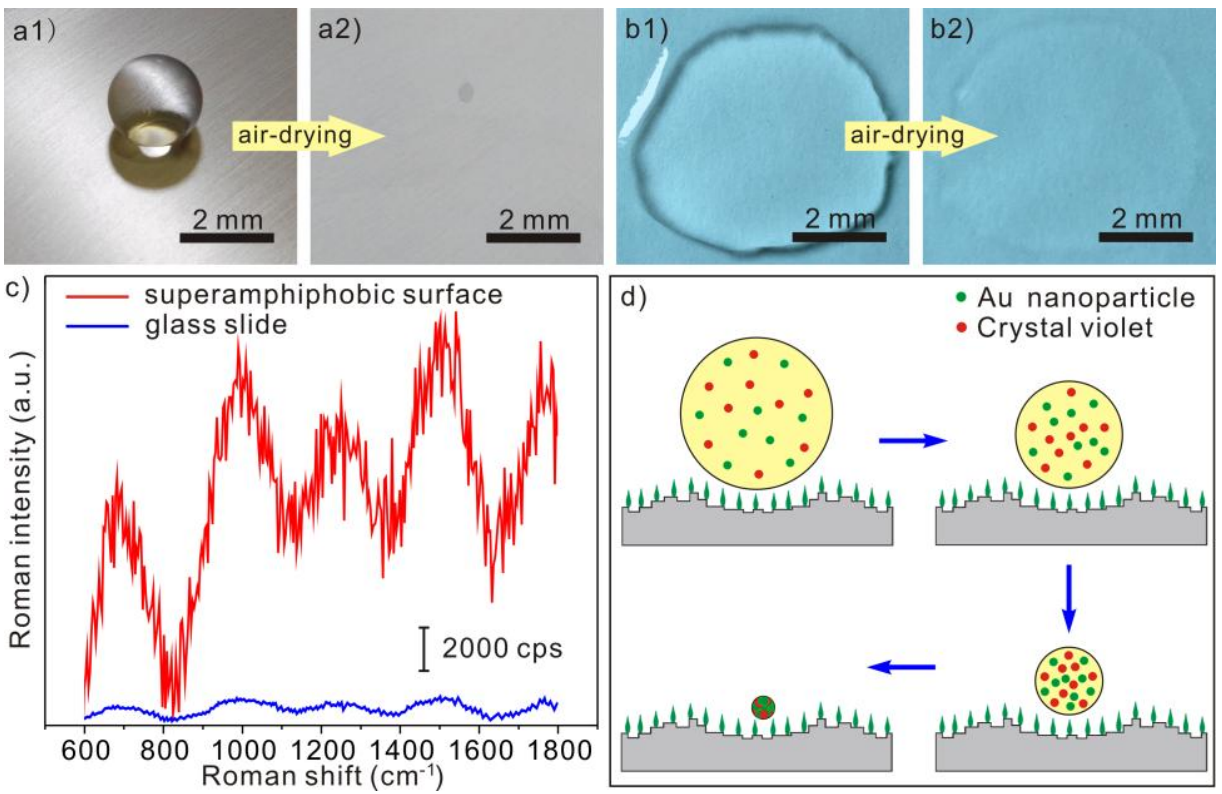

Fig. 11. Optical images of the air-dried morphology changes for a water droplet $(25 \mu \mathrm{L})$ containing crystal violet and Au nanoparticles on Al-Mg alloys surface processed with P-E-B-F steps (a) and the glass slide (b). (c) referring to the surface-enhanced Raman scattering analysis and detection of the analytes at a random selected point on the dried areas of (a2) and (b2). (d) corresponding to the schematic process of a droplet evaporation on the fabricated superamphiphobic surface. 
Table 1. The equivalent circrsuit components parameters after electrochemical fittings.

\begin{tabular}{ccccccc}
\hline Samples & $\mathrm{R}_{\mathrm{s}}\left(\Omega . \mathrm{cm}^{2}\right)$ & $\mathrm{R}_{\mathrm{ct}}\left(\Omega . \mathrm{cm}^{2}\right)$ & $\mathrm{CPE}\left(\mu \mathrm{F} . \mathrm{cm}^{-2}\right)$ & $\mathrm{R}_{\mathrm{c}}\left(\Omega . \mathrm{cm}^{2}\right)$ & $\mathrm{C}_{\mathrm{dl}}\left(\mu \mathrm{F} . \mathrm{cm}^{-2}\right)$ & $\beta(\%)$ \\
\hline P & 7.5 & 1752 & 33.5 & - & - & - \\
P-F & 10.7 & 5331 & 147.9 & 598.3 & 23.4 & 67.1 \\
P-E-F & 10.1 & 12420 & 156.1 & 191.4 & 13.5 & 85.9 \\
P-B-F & 8.1 & 10836 & 209.9 & 96.35 & 47.1 & 83.8 \\
P-E-B-F & 9.6 & 17530 & 152.9 & 139.8 & 18.24 & 90.0 \\
\hline
\end{tabular}




\section{Graphical Abstract}

A superamphiphobic surface with binary hierarchical micro/nanostructures is obtained by polishing, etching, boiling and fluoroalkyl-silane modification treatments on Al-Mg alloy sheet with improved anticorrosion behavior, which can also be applied in concentrators for SERS analysis of toxic and pollutive ions.

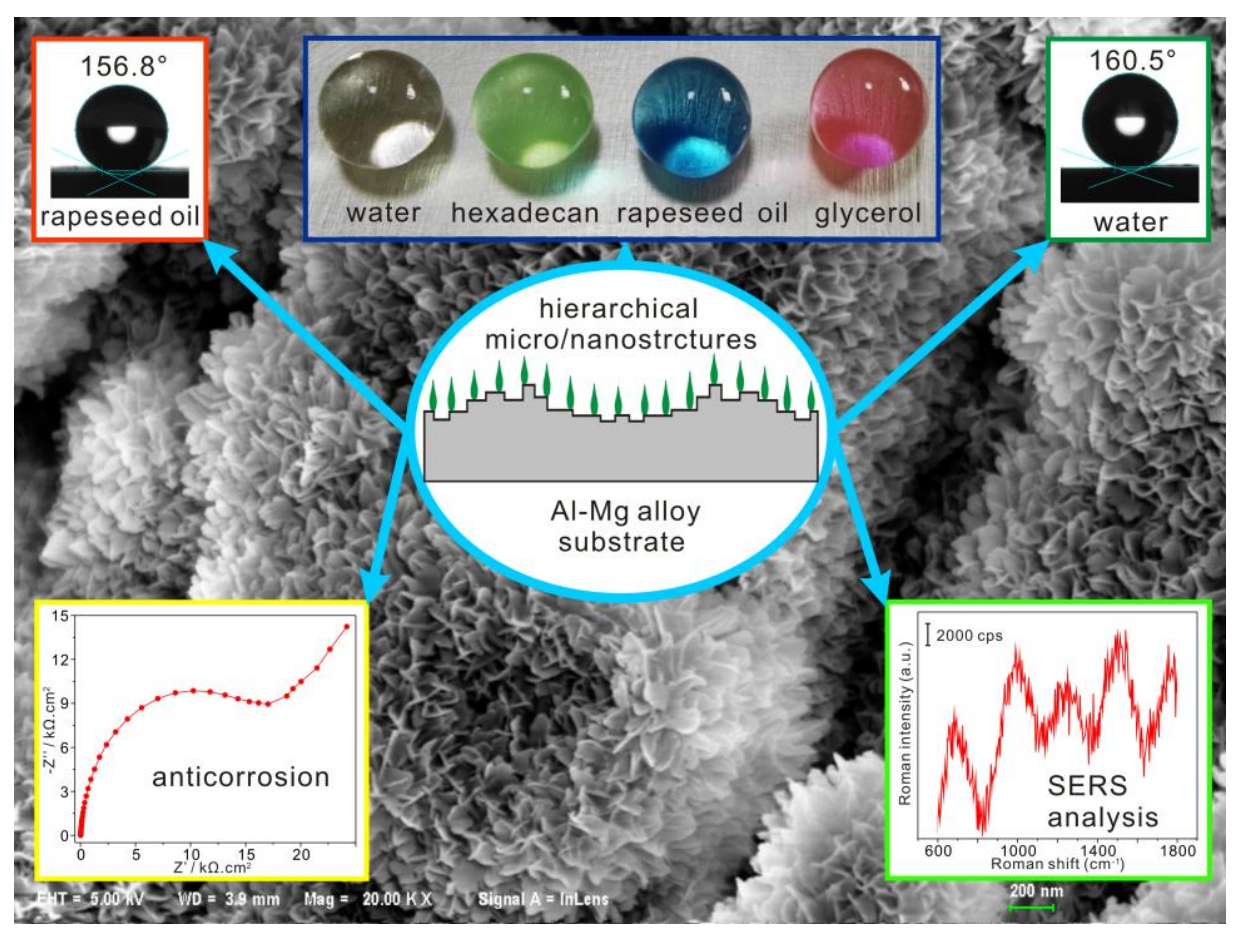

